\title{
Microbial communities and symbionts in the hard tick Haemaphysalis longicornis (Acari: Ixodidae) from north China
}

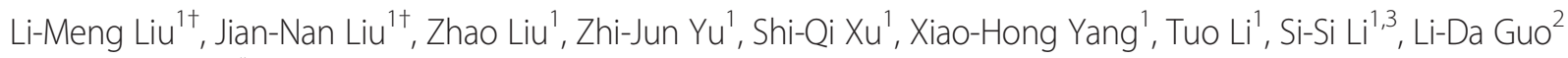
and Jing-Ze Liü ${ }^{1 *}$

\begin{abstract}
Background: Close relationships between ticks and microbial communities are important for tick fitness and pathogen colonization and transmission. Haemaphysalis longicornis, distributed widely in China, can carry and transmit various pathogens and pose serious damages to public health and economics. However, little is known about the broader array of microbial communities and symbionts in $\mathrm{H}$. longicornis under natural conditions. In the present study, we investigated the composition of bacterial communities associated with H. longicornis and evaluated the putative symbionts.

Methods: The eubacterial 16S rRNA gene clone libraries of $\mathrm{H}$. longicornis were constructed and analyzed by restriction fragment length polymorphism (RFLP) and DNA sequencing. In addition, diagnostic PCR was performed to assess the prevalence, vertical transmission and infection sites of the symbionts in $\mathrm{H}$. longicornis.

Results: Vertically-transmitted symbionts, potential pathogens and allochthonous nonpathogenic bacteria were identified from the field-collected H. longicornis. Three types of symbionts (Coxiella-like, Arsenophonus-like and Rickettsia-like symbionts) were identified in a single host simultaneously. A series of analyses revealed the vertical transmission, prevalence, and infection sites of these symbionts. However, only Coxiella-like bacteria were transmitted stably in the laboratory-reared ticks. In addition, we identified a novel Coxiella-like agent with 95.31\% sequence similarity to the taxon described previously.

Conclusions: The present study demonstrated that natural H. longicornis harboured a diverse array of microbial communities. Three types of symbionts were identified in a single host simultaneously. Moreover, high prevalence, vertical transmission and the infection sites supported an obligate symbiotic association between Coxiella symbiont and its host. The role of Coxiella symbiont in the host fitness and the interaction among microbial communities remained to be elucidated. Our investigation of microbial communities in the ticks revealed the complexity of ecological interactions between host and microbe and provided insight for the biological control of ticks.
\end{abstract}

Keywords: Haemaphysalis longicornis, Microbial communities, Coxiella-like symbiont, Arsenophonus-like symbiont, Rickettsia-like symbiont

\footnotetext{
* Correspondence: jzliu21@heinfo.net

${ }^{\dagger}$ Equal contributors

'Key Laboratory of Animal Physiology, Biochemistry and Molecular Biology of Hebei Province, College of Life Sciences, Hebei Normal University, Nanerhuan Eastern Road, No. 20, Shijiazhuang, Hebei, P. R. China

Full list of author information is available at the end of the article
} 


\section{Background}

As obligate blood-feeding arthropods, ticks feed on terrestrial vertebrates and are one of the most important disease vectors worldwide. Ticks are involved in carrying and transmitting a diverse group of pathogenic bacteria, which exert severely negative impacts on human health, livestock production as well as wildlife [1-3]. Hard ticks (Ixodidae) usually have three life stages (larva, nymph, adult) in their lifespan and feed on distinct host species at different developmental stages. Thus, they are prone to acquiring various pathogens and spreading among vertebrate species during the whole life cycle [4].

In addition to pathogens, vertically-transmitted symbionts and foreign nonpathogenic bacteria also colonize the ticks [5-7]. Symbionts are closely associated with the host fitness [8,9] and transmission and virulence of pathogens $[10,11]$. To date, it is well-known that ticks harbour various symbionts, including Coxiella [12], Francisella [13], Wolbachia [14], Rickettsia [15], Arsenophonus [16], Candidatus Midichloria mitochondrii [17]. Moreover, some of them have crucial effects on the biological characteristics of ticks. For example, the obligate Coxiellalike symbiont manipulates the reproduction of the host Amblyomma americanum [18-20]. Ca. Midichloria mitochondrii, the symbiont of Ixodes ricinus, has the unique ability to enter and destroy mitochondria within ovarian cells of host [21,22], which is coupled with the process of engorgement and molt [23,24]. In addition, colonization of Dermacentor variabilis by $R$. peacockii can prevent secondary infection with other Rickettsia bacteria, including pathogenic species [25]. Clay [5] found that the infection frequency of Arsenophonus was negatively correlated to Rickettsia in A. americanum, indicating that infection with symbionts may affect the microbial community structure and their interaction.

Ticks could also obtain allochthonous nonpathogenic bacteria by sucking host blood and contact with the natural environment [26-28]. Although allochthonous bacteria are not directly related to the pathogenicity of hosts, they can reflect the habitats of hosts and even have the potential to impact on the density and transmission of host-borne agents [29]. Overall, diverse microbial communities can exert great impact on the fitness of ticks and the colonization and transmission of tick-borne pathogens.

Haemaphysalis longicornis (Acari: Ixodidae), a threehost tick, extensively distributed in China [30], Korea, Japan, New Zealand, and Australia [31,32], has inflicted serious damage on public health and economics. It is reported that this tick species transmitted a variety of pathogens [33,34], including Babesia microti [35], Ehrlichia chaffeensis [36], Anaplasma bovis [37], A. phagocytophilum [38], C. burnetii [39], Spotted fever group rickettsiae [40], and Borrelia burgdorferi [41]. With regard to the human health and economic significance, pathogens carried by $H$. longicornis have been well investigated in China [42-47]. However, little is known about the broader array of the microbial community in $H$. longicornis under natural conditions.

In the present study, we investigated the composition of bacterial communities associated with $H$. longicornis using PCR-RFLP and DNA sequencing approaches, and evaluated the putative symbionts.

\section{Methods}

\section{Sample collection and storage}

$H$. longicornis samples were collected in Xiaowutai National Natural Reserve Area in China by flag dragging. A total of 500 ticks were collected and stored at $-80^{\circ} \mathrm{C}$. We also collected 1,000 ticks, which were reared on rabbits as described by Liu et al. [48]. Colonies of these ticks were reared on the ears of rabbits. Rabbits were maintained in a room with $50-55 \%$ relative humidity $(\mathrm{RH})$ at $25-27^{\circ} \mathrm{C}$ and exposed to daylight. After detachment, ticks were collected and incubated in cottonplugged glass tubes filled with folded filter paper in an incubator with $75 \pm 5 \% \mathrm{RH}$ and $6 / 18 \mathrm{~h}$ of L/D cycle at $26 \pm 1{ }^{\circ} \mathrm{C}$. The protocol of all animal experiments was approved by the Institutional Animal Care and Use Committee of Hebei Normal University.

\section{DNA extraction}

The genomic DNA for constructing eubacterial $16 \mathrm{~S}$ rRNA gene libraries were extracted from a group of adults (10 females and 10 males). To assess the prevalence, vertical transmission and infection sites, DNA was isolated from individual field-collected adults, and pooled ticks at different developmental stages (500 eggs, 200 larvae and 50 nymphs) and different tissues (ovaries, salivary glands, Malpighian tubules and midguts), respectively. Before DNA extraction, the whole tick samples were sterilized as described previously [5], and dissected tissues were washed in sterile phosphatebuffered saline (PBS) (137 mM NaCl, $2.7 \mathrm{mM} \mathrm{KCl}$, $4.3 \mathrm{mM} \mathrm{Na}_{2} \mathrm{HPO}_{4} \cdot 7 \mathrm{H}_{2} \mathrm{O}, 1.4 \mathrm{mM} \mathrm{KH} \mathrm{PO}_{4}, \mathrm{pH}$ 7.4) for three times. Subsequently, all samples were snap-frozen in liquid nitrogen and purified using the DNeasy Tissue Kit (Qiagen, Germany) according to the manufacturer's instructions.

\section{Eubacterial 16S rRNA gene library construction, RFLP analysis and sequencing}

The eubacterial 16S rRNA gene clone library was constructed by amplifying about 1500 bp fragment of $16 \mathrm{~S}$ rRNA gene using eubacterial universal primers $27 \mathrm{~F} /$ 1492R [49]. Purified PCR products were cloned into pEASY-T1 vector (TransGen, China) and transformed into Escherichia coli TOP10 competent Cell (TransGen, 
China). The positive clones were subjected to restriction fragment length polymorphism (RFLP) analyses using both HaeIII and RsaI restriction endonucleases. Sequencing of the positive clones with different restriction fragment patterns were performed by Sangon Biotech Company (China).

\section{Phylogenetic analyses}

The 16S rRNA gene sequences of the most closely related species were retrieved from GenBank and then aligned. The similarity analyses were performed using the CLUSTAL_W program [50]. The phylogenetic tree was constructed using neighbour-joining method implemented in MEGA4.0 [51]. The stability of the tree clustering was evaluated by means of a bootstrap analysis of 1000 datasets [52].

\section{Diagnostic PCR}

To assess their prevalence, vertical transmission and infection site of symbionts, diagnostic PCR assay was performed with four sets of specific primers (Table 1). The PCR reaction contained $20 \mathrm{mM}$ Tris- $\mathrm{HCl}(\mathrm{pH}$ 8.4), $50 \mathrm{mM} \mathrm{KCl}, 1.5 \mathrm{mM} \mathrm{MgCl}, 200 \mu \mathrm{M}$ each dNTP, $2.5 \mathrm{U}$ Platinum Taq DNA Polymerase (Invitrogen, America), and $0.5 \mathrm{mM}$ each primer. PCR cycling conditions were as follows: 1 cycle of $94^{\circ} \mathrm{C}$ for $2 \mathrm{~min} ; 30$ cycles of $94^{\circ} \mathrm{C}$ for $30 \mathrm{~s}, 55^{\circ} \mathrm{C}$ for $30 \mathrm{~s}$, and $72^{\circ} \mathrm{C}$ for $15 \mathrm{~s}$, and $72^{\circ} \mathrm{C}$ for $10 \mathrm{~min}$.

\section{Results}

\section{Diversity of bacterial communities from field-collected H. longicornis}

Our results revealed diverse microbial communities associated with field-collected $H$. longicornis (Table 2). In the $16 \mathrm{~S}$ rRNA gene clone libraries, the most abundant sequences (belonged to Coxiella and designated as CLS-Hl) in both males and females share $99.5 \%$ similarity to the symbiont of H. longicornis (GenBank: AB001519) [53]. In females, the second abundant sequence (designated as NCLS-Hl) belonged to Coxiella, sharing 95.3\% similarity to Coxiella-like symbionts of Rhipicephalus sanguine (GenBank: D84559). Following NCLS-Hl, sequences belonged to Rickettsia (designated as RLS-Hl) and E. coli. Rickettsia bacteria shared the highest sequence similarity (99.8\%) with symbiotic Rickettsia of D. varibilis (GenBank: U55820) [54]. In males, the second abundant microbes (designated as ALS-Hl) belonged to Arsenophonus, sharing over $99.5 \%$ and $97.9 \%$ similarity to symbionts of D. silvarum (GenBank: JN866582) [55] and D. variabilis (GenBank: AY265342) [56], respectively. Following ALS-Hl, there were RLS-Hl and NCLS-Hl. Interestingly, the top four abundant bacteria in females were consistent with those in males.

\section{Symbionts}

OmpA gene sequence analyses revealed that RLS-Hl belonged to $\mathrm{Ca}$. Rickettsia hebeiii, with $99.1 \%$ sequence similarity [57]. To confirm vertical transmission of symbionts, eggs and the first generation of laboratory-reared ticks (larvae, nymphs and adults) was tested by diagnostic PCR assay. The putative symbionts were found in all samples detected, with the exception of NCLS-Hl. These results indicated that CLS-Hl, ALS-Hl and RLS-Hl were inherited from progeny to the next generation, while NCLS-Hl was not (Figure 1). To determine the stability of vertical transmission, we investigated the presence of each bacterium in the 7th generation of laboratory-reared ticks (F7). The results showed only CLS-Hl was detected in F7 ticks, while ALS-Hl and RLS-Hl were not, suggesting that CLS-Hl can be maintained stably in laboratory-reared ticks.

In natural field populations, CLS-Hl showed $100 \%$ infection rate; ALS-Hl occurred in 33.3\% (14/36) females and $83.3 \%(10 / 12)$ males; the prevalence of RLS-Hl was $88.9 \%(32 / 36)$ and $100 \%(12 / 12)$ in females and males, respectively. In the laboratory population, the prevalence of CLS-Hl was $100 \%$.

Table 1 Oligonucleotide primers used for PCR amplification and sequencing

\begin{tabular}{|c|c|c|c|c|c|c|}
\hline Primer name & $\begin{array}{l}\text { Genera or } \\
\text { Species }\end{array}$ & Target gene & Nucleotide sequence $\left(5^{\prime}-3^{\prime}\right)$ & Annealing temperature $\left({ }^{\circ} \mathrm{C}\right)$ & $\begin{array}{l}\text { Approx product } \\
\text { size (bp) }\end{array}$ & Reference \\
\hline CLS F & Coxiella & $16 \mathrm{~S}$ rRNA & CACGTAGGAATCTACCTTGTAG & 55 & 90 & 55 \\
\hline CLS R & & & CGTTTTGTCCGAAGAAATTAT & & & \\
\hline ALS $82 \mathrm{~F}$ & Arsenophonu & $16 \mathrm{~S}$ rRNA & AGGGAGCTTGCTTCCTGGCCGG & 59 & 130 & 55 \\
\hline ALS 198R & & & CGAAGGTGTGAGGCCTAATGG & & & \\
\hline Rickettsia $354 \mathrm{~F}$ & Rickettsia & $16 \mathrm{~S}$ rRNA & CAGCAATACCGAGTGAGTGATGAAG & 56 & 350 & 69 \\
\hline Rickettsia 647R & & & AGCGTCAGTTGTAGCCCAGATG & & & \\
\hline NCLS F & NCLS & $16 \mathrm{~S}$ rRNA & TCCCTGGCGGCGAGTGG & 55 & 110 & This study \\
\hline NCLS R & & & CGTATTAGAGATTAGAGAAACC & & & \\
\hline $\operatorname{Rr} 190.70 p$ & Rickettsia & rompA & ATGGCGAATATTTCTCCAAAA & 48 & 540 & 57 \\
\hline $\operatorname{Rr} 190.602 n$ & & & GTTCCGTTAATGGCAGCATCT & & & \\
\hline
\end{tabular}


Table 2 Eubacterial 16S rRNA gene clone libraries from females and males of Haemaphysalis longicornis

\begin{tabular}{|c|c|c|c|c|}
\hline Classification & Closest taxon (GenBank No.) & Identity \% & Sequences $^{\#}(\mathrm{~F} / \mathrm{M})^{*}$ & Accession No. (GenBank) \\
\hline \multicolumn{5}{|l|}{ Proteobacteria } \\
\hline \multirow[t]{4}{*}{ a-proteobacteria } & Rhizobium spp. (EF363715) & $99 \%$ & $4 / 0$ & JN866565 \\
\hline & Rickettsia spp. (CP003319) & $99 \%$ & $9 / 12$ & JN866571 \\
\hline & Devosia psychrophila (GU441678) & $98 \%$ & $0 / 1$ & JN866597 \\
\hline & Asticcacaulis excentricus (CP002395) & $99 \%$ & $2 / 0$ & JN866569 \\
\hline$\beta$-proteobacteria & Janthinobacterium lividum (EU275366) & $99 \%$ & $0 / 5$ & JN866578 \\
\hline \multirow[t]{6}{*}{ ү-proteobacteria } & Escherichia coli (CP001673) & $100 \%$ & $8 / 7$ & JN866566 \\
\hline & Moraxella osloensis (AB643592) & $99 \%$ & $4 / 0$ & KF421818 \\
\hline & Pseudomonas spp. (AB334768) & $99 \%$ & $0 / 7$ & JN866577 \\
\hline & Coxiella-like symbionts of $\mathrm{H}$. longicornis $(\mathrm{AB} 001519)^{\S}$ & $99 \%$ & $36 / 19$ & JN866564 \\
\hline & Coxiella-like symbionts of R. sanguine $(\mathrm{D} 84559)^{\S}$ & $95 \%$ & $21 / 11$ & JN866567 \\
\hline & Arsenophonus-like symbionts of Dermacentor silvarum (JN866582) $)^{\S}$ & $99 \%$ & $5 / 16$ & JN866572 \\
\hline \multicolumn{5}{|l|}{ Bacteroidetes } \\
\hline \multirow[t]{2}{*}{ Sphingobacteria } & Mucilaginibacter sp. (GU139695) & $98 \%$ & $1 / 0$ & JN866568 \\
\hline & Sphingomonas asaccharolytica (AY509241) & $98 \%$ & $0 / 1$ & JN866579 \\
\hline \multicolumn{5}{|l|}{ Actinobacteria } \\
\hline \multirow[t]{2}{*}{ Actinobacteria } & Williamsia maris (NR024671) & $99 \%$ & $0 / 2$ & JN866598 \\
\hline & Conexibacter woesei (CP001854) & $98 \%$ & $0 / 1$ & JN866581 \\
\hline
\end{tabular}

"Source of the sequences from female ticks (F) or male ticks (M).

\#Sequences indicate the number of 16S rRNA gene sequences obtained for each 16S rRNA gene clone libraries.

${ }^{\S}$ Sequences are related phylogenetically to previously reported tick-associated bacteria.

Analysis of the infection site showed that three types of symbionts infected all tissues detected (accessory glands, testes, salivary glands, midguts) and there is no significant difference among all tissues in males. In females, CLS-Hl colonized specifically in the ovaries and Malpighian tubules, while ALS-Hl and RLS-Hl infected all tissues tested (ovaries, salivary glands, Malpighian tubules and midguts) (Figure 2).

\section{Discussion}

In this study, we showed that the natural $H$. longicornis harboured a diverse group of bacterial species. Previous studies have shown that some tick species were colonized with complex microbial communities, including $A$. americanum, I. ricinus, I. scapularis and $R h$. microplus [5-7,26-28,58,59]. Investigation of microbiota in the ticks revealed the complexity of ecological interactions between host and microbe and provided insight for the biological control of ticks.

\section{Symbionts}

Interestingly, some sequences were phylogenetically related to previously reported tick-associated bacteria, including (1) two types of Coxiella-like bacteria, CLS-Hl and NCLS-Hl, (2) Arsenophonus-like symbiont, ALS-Hl, (3) Rickettsia-like symbiont, RLS-Hl. It is now widely accepted that the co-infection with multiple symbionts

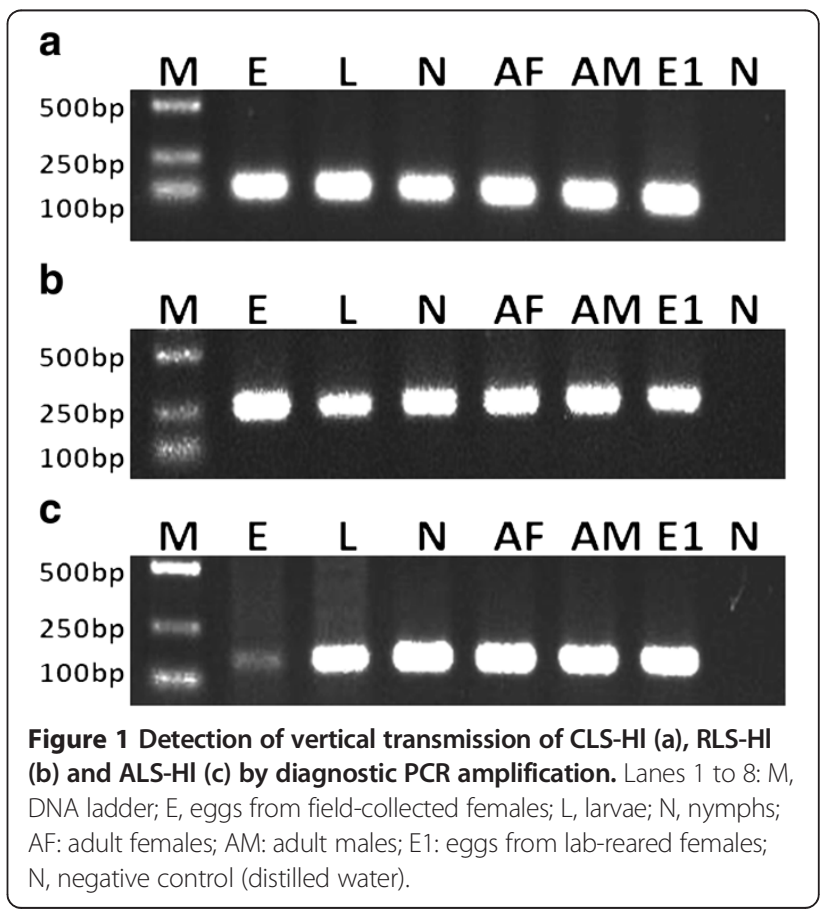




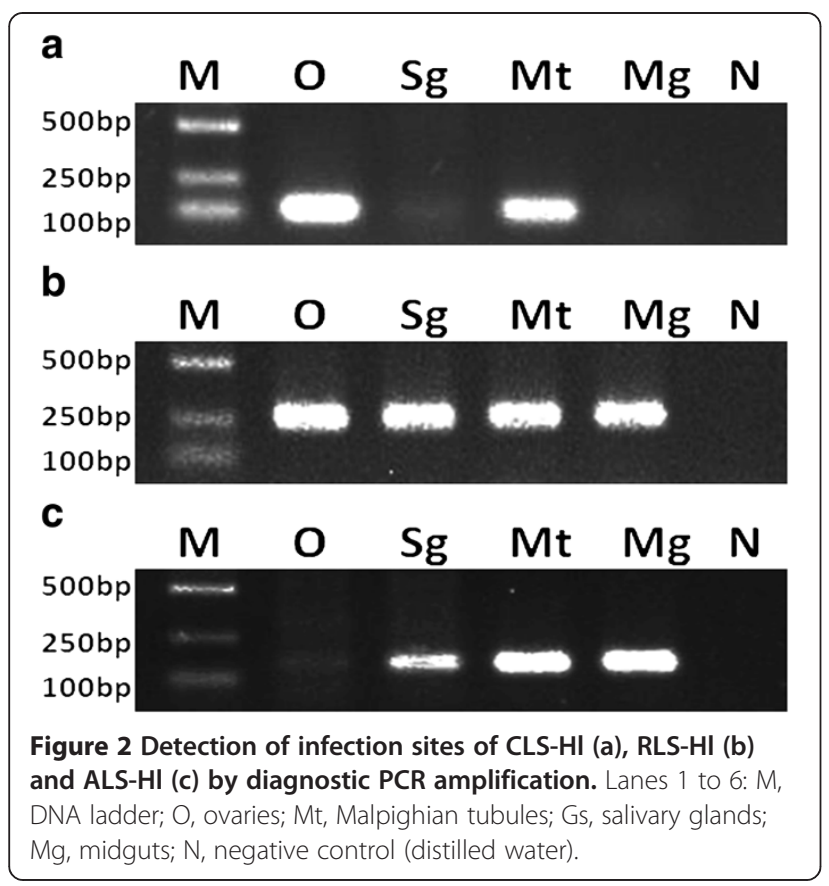

occurs in many arthropod hosts [60]. However, coinfection with symbionts has been demonstrated only in a few tick species, such as A. americanum [5], Ornithodoros moubata [61], D. silvarum [55] and Rh. sanguineus [62]. We reported here for the first time that Coxiella-like, Arsenophonus-like and Rickettsia-like symbionts were detected simultaneously in wild $H$. longicornis. Interestingly, we identified two different types of Coxiella. CLS-Hl, with 95.1\% similarity to the C. burnetii, shared $99.5 \%$ sequence identify with the symbionts of $H$. longicornis previously reported $[39,53]$. However, NCLS-Hl, with $95.1 \%$ and $95.3 \%$ similarity to the C. burnetii and symbionts of Rh. sanguine, respectively, was regarded as a novel Coxiella-like agent and has never been described before. Phylogenetic analyses revealed (Figure 3) that CLS-Hl and NCLS-Hl form an individual clade, although both of them belong to the cluster of hard tick species (Ixodidae). CLS-Hl was clustered with symbionts of Haemphysalis (H. longicornis and H. shimoga), while NCLS-Hl was grouped together with the symbionts of Rhipicephalus (Rh. sanguineus and $R h$. turanicus). However, the determination of vertical transmission does not support that NCLS-Hl was a symbiont. Further studies are needed to confirm the pathogenicity of this novel Coxiella agent to vertebrate hosts.

In ticks, Coxiella bacteria are the most common agent, exhibiting diverse genotypes in different tick species [5,12,63-68]. By comparing the phylogeny between the tick mitochondrial 16S rRNA gene and the Coxiella agents carried by ticks, Almeida [12] showed that ticks were phylogenetically associated with their Coxiella agents, suggesting that Coxiella symbionts and ticks shared a long co-evolution process. In H. longicornis, Coxiella symbionts from different areas, such as Japan [53] and Korea [39], shared identical genotypes. This wide geographical distribution indicates that Coxiella symbionts form ancient symbiotic associations with their host before spreading.

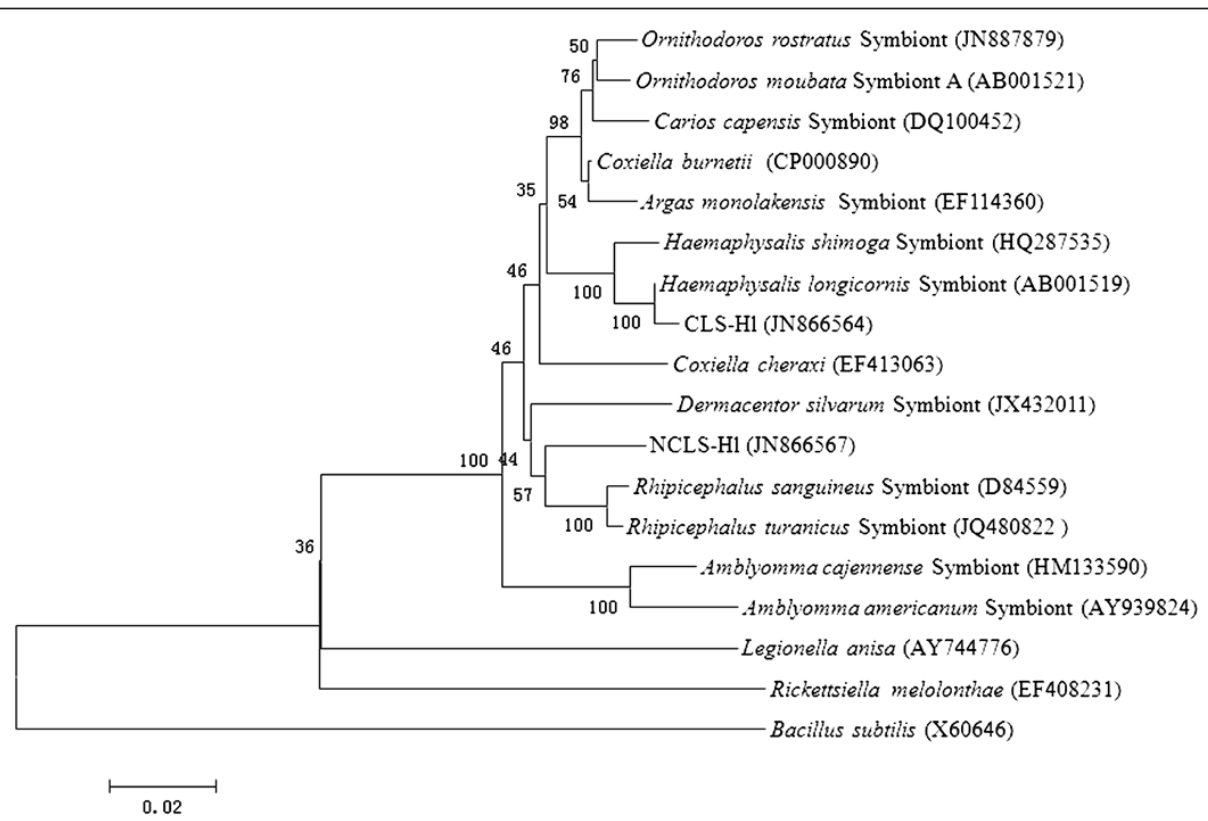

Figure 3 Phylogenetic tree of two types of Coxiella-like bacteria based on 16S rRNA gene sequence similarity. The tree was rooted with Bacillus subtilis (GenBank: X60646) and constructed using neighbour-joining method and clustering nodes were also recovered in maximum likelihood method. Numbers at nodes represent the levels of bootstrap support (\%) based on neighbour-joining analysis of 1000 replicated data sets. GenBank accession numbers are given in parentheses. Bar represents $2 \%$ sequence divergence. 
Previous studies suggested that Coxiella symbionts in A. americanum, with $100 \%$ infection, vertical transmission, reduced-genome, regulation of the reproduction of the host, was closely related to the fitness of the ticks. Besides, in O. rostratus [12], D. silvarum [55] and $R h$. sanguineus [62], Coxiella-like symbionts exhibited nearly perfect prevalence and were presumed as obligate symbionts. In this study, $100 \%$ infection rate, perfect vertical transmission, colonization in specialized tissues, CLS-Hl was regarded as obligate and contributed to the fitness of ticks.

Arsenophonus is one of the four major inherited symbionts of arthropods with an infection rate of 5\% [60]. Arsenophonus has been reported to infect $A$. americanum [5], D. variablilis [16], D. andersoni [16] and D. silvarum [55]. Interestingly, the sequence of ALS-Hl was identical to that of $D$. silvarum collected from the same place as the $H$. longicornis, possibly suggesting horizontal transmission of Arsenphonus-like symbionts between different genera of ticks. Previous studies also provided evidence of horizontal transmission of symbionts between D. variabilis and D. andersoni [16]. Therefore, Arsenophonus possessed not only intragenus, but also intergenus horizontal transmission.

Rickettsia, with both symbiotic and pathogenic lifestyle, inhabits multiple tick species. Pathogenic rickettsiae have been extensively investigated, while only few studies on symbiotic rickettsiae have been reported. To date, Rickettsia-like symbionts have been identified in D. variabilis [54], D. andersoni [69], D. silvarum [55] I. scapularis [15] and A. americanum [5]. In this study, we showed molecular evidence for the vertical transmission of the Rickettsia-like symbiont (Ca. Rickettsia hebeiii) in $H$. longicornis. Moreover, high prevalence in the natural environment suggested interaction between RLS-Hl and their hosts.

However, RLS-Hl and ALS-Hl were not detected in F7 laboratory-reared ticks, suggesting that they cannot be maintained stably from one generation to the progeny in the laboratory. This phenomenon was also observed in I. ricinus, whose symbionts IricES1 were lost from female adults to progeny in the laboratory [70]. The transmission efficiency of symbionts decreased significantly in the laboratory, which was partially due to the competition among symbionts and bottlenecks during vertical transmission [71]. Alternatively, transmission reduction may be due to temperature differences between natural and laboratory environments [72].

\section{Conclusions}

A diverse array of microbial communities were identified from field-collected $H$. longicornis. Three types of symbionts were detected in a single host simultaneously. Moreover, analysis on the prevalence, vertical transmission and infection sites supported obligate symbiotic association between Coxiella symbionts and its host. The role of Coxiella symbionts in the host fitness and the interaction among microbial communities remains to be elucidated. Our investigation of microbial communities in the ticks revealed the complexity of ecological interactions between host and microbe and provided insight for the biological control of ticks.

\section{Abbreviations}

F7: The 7th generation of laboratory-reared ticks; CLS-HI: Coxiella-like symbiont of H. longicornis; NCLS-HI: Novel Coxiella-like symbiont of H. longicornis; RLS$\mathrm{HI}$ : Rickettsia-like symbiont of H. longicornis; ALS-HI: Arsenophonus-like symbiont of $\mathrm{H}$. longicornis.

\section{Competing interests}

The authors declare that they have no competing interests.

\section{Authors' contributions}

Liu L-M and Liu J-Z conceived and designed the study, constructed $16 \mathrm{~S}$ rRNA gene libraries and performed RFLP analyses, drafted the manuscript, and critically revised the manuscript. Liu J-N carried out RFLP analyses and diagnostic PCR. Liu Z, Yu Z-J, Xv S-Q and Yang X-H, participated in sample collection, study implementation and data collection and helped to revise the manuscript. Li T, Li S-S and Guo L-D participated in sample collection and tick feeding. All authors read and approved the final manuscript.

\section{Acknowledgements}

This work was supported by grants from the National Natural Science Foundation of China (Grant No. 31272372) and the Specialized Research Fund for the Doctoral Program of Higher Education of China (Grant No. 20131303130001)

\section{Author details}

${ }^{1}$ Key Laboratory of Animal Physiology, Biochemistry and Molecular Biology of Hebei Province, College of Life Sciences, Hebei Normal University, Nanerhuan Eastern Road, No. 20, Shijiazhuang, Hebei, P. R. China. ${ }^{2}$ Department of Environment and Chemical Engineering, Hebei College of Industry and Technology, Hongqi Road, No. 626, Shijiazhuang, Hebei, P. R. China. ${ }^{3}$ College of Life Sciences, Hengshui University, Heping Western Road, No. 1088, Hengshui, Hebei, P. R. China.

Received: 1 August 2013 Accepted: 18 October 2013

Published: 28 October 2013

\section{References}

1. de la Fuente J, Estrada-Pena A, Venzal JM, Kocan KM, Sonenshine DE: Overview: ticks as vectors of pathogens that cause disease in humans and animals. Front Biosci 2008, 13:6938-6946.

2. Estrada-Peña A, Jongejan F: Ticks feeding on humans: a review of records on human-biting Ixodoidea with special reference to pathogen transmission. Exp Appl Acarol 1999, 23:685-715.

3. Anderson JF, Magnarelli LA: Biology of ticks. Infect Dis Clin North Am 2008, 22:195-215.

4. Kaufman WR: Ticks: physiological aspects with implications for pathogen transmission. Ticks Tick Borne Dis 2010, 1:11-22.

5. Clay K, Klyachko O, Grindle N, Civitello D, Oleske D, Fuqua C: Microbial communities and interactions in the lone star tick, Amblyomma americanum. Mol Ecol 2008, 17:4371-4381.

6. Benson MJ, Gawronski JD, Eveleigh DE, Benson DR: Intracellular symbionts and other bacteria associated with deer ticks (Ixodes scapularis) from Nantucket and Wellfleet, Cape Cod, Massachusetts. Appl Environ Microbiol 2004, 70:616-620.

7. van Overbeek L, Gassner F, van der Plas CL, Kastelein P, Nunes-da Rocha U, Takken W: Diverisity of Ixodes ricinus tick-associated bacterial communities from different forests. FEMS Microbiol Ecol 2008, 66:72-84.

8. Dale C, Moran NA: Molecular interactions between bacterial symbionts and their host. Cell 2006, 126:453-465. 
9. Gosalbes MJ, Latorre A, Lamelas A, Moya A: Genomics of intracellular symbionts in insects. Int J Med Microbiol 2010, 300:271-278.

10. Haine ER: Symbiont-mediated protection. Proc R SoC B 2007, 275:353-361

11. Thrall PH, Hochberg ME, Burdon JJ, Bever JD: Coevolution of symbiotic mutualists and parasites in a community context. Trends Ecol Evol 2007, 22:120-126.

12. Almeida AP, Marcili A, Leite RC, Nieri-Bastos FA, Domingues LN, Martins JR, Labtuna MB: Coxiella symbiont in the tick Ornithodoros rostratus (Acari: Argasidae). Ticks Tick Borne Dis 2012, 3:203-206.

13. Ivanov IN, Mitkova N, Reye AL, Hübschen JM, Vatcheva-Dobrevska RS, Dobreva EG, Kantardjiev TV, Muller CP: Detection of new Francisella-like tick endosymbionts in Hyalomma spp. and Rhipicephalus spp. (Acari: Ixodidae) from Bulgaria. Appl Environ Microbiol 2011, 77:5562-5565.

14. Zhang X, Norris DE, Rasgon JL: Distribution and molecular characterization of Wolbachia endosymbionts and filarial nematodes in Maryland populations of the lone star tick (Amblyomma americanum). FEMS Microbiol Ecol 2011, 77:50-56.

15. Gillespie JJ, Joardar V, Williams KP, Driscoll T, Hostetler JB, Nordberg E, Shukla M, Walenz B, Hill CA, Nene VM, Azad AF, Sobral BW, Caler E: A Rickettsia genome overrun by mobile genetic elements provides insight into the acquisition of genes characteristic of an obligate intracellular lifestyle. J Bacteriol 2012, 194:376-394.

16. Dergousoff SJ, Chilton NB: Detection of a new Arsenophonus-type bacterium in Canadian populations of the Rocky Mountain wood tick, Dermacentor andersoni. Exp Appl Acarol 2010, 52:85-91.

17. Sassera D, Beninati T, Bandi C, Bouman EAP, Sacchi L, Fabbi M, Lo N 'Candidatus Midichloria mitochondrii', an endosymbiont of the tick Ixodes ricinus with a unique intramitochondrial lifestyle. Int I Syst Evol Microbiol 2006, 56:2535-2540.

18. Klyachko O, Stein BD, Grindle N, Clay K, Fuqua C: Localization and visualization of a Coxiella-type symbiont within the lone star tick, Amblyomma americanum. Appl Environ Microbiol 2007, 73:6584-6594.

19. Jasinskas A, Zhong J, Barbour AG: Highly prevalent Coxiella sp. bacterium in the tick vector Amblyomma americanum. Appl Environ Microbiol 2007. 73:334-336

20. Zhong J, Jasinskas A, Barbour AG: Antibiotic treatment of the tick vector Amblyomma americanum reduced reproductive fitness. PLoS One 2007, 2:e405.

21. Beninati T, Lo N, Sacchi L, Genchi C, Noda H, Bandi C: A novel alphaproteobacterium resides in the mitochondria of ovarian cells of the tick Ixodes ricinus. Appl Environ Microbiol 2004, 70:2596.

22. Sacchi L, Bigliardi E, Corona S, Beinati T, Lo N, Franceschi A: A symbiont of the tick /xodes ricinus invades and consumes mitochondria in a mode similar to that of the parasitic bacterium Bdellovibrio bacteriovorus. Tissue Cell 2004, 36:43-53.

23. Sassera D, Lo N, Bouman EA, Epis S, Mortarino M, Bandi C: "Candidatus Midichloria" endosymbionts bloom after the blood meal of the host, the hard tick Ixodes ricinus. Appl Environ Microbiol 2008, 74:6138-6140.

24. Epis S, Mandrioli M, Genchi M, Montagna M, Sacchi L, Pistone D, Sassera D: Localization of the bacterial symbiont Candidatus Midichloria mitochondrii within the hard tick Ixodes ricinus by whole-mount FISH staining. Ticks Tick Borne Dis 2013, 4:39-45.

25. Macaluso KR, Sonenshine DE, Ceraul SM, Azad AF: Rickettsial infection in Dermacentor variabilis (Acari: Ixodidae) inhibits transovarial transmission of a second Rickettsia. J Med Entomol 2002, 39:809-813.

26. Schabereiter-Gurtner C, Lubitz W, Rölleke S: Application of broad-range $16 S$ rRNA PCR amplification and DGGE fingerprinting for detection of tick-infecting bacteria. J Microbiol Methods 2003, 52:251-260.

27. Andreotti R, de León AA P, Dowd SE, Guerrero FD, Bendele KG, Scoles GA: Assessment of bacterial diversity in the cattle tick Rhipicephalus (Boophilus) microplus through tag-encoded pyrosequencing. BMC Microbiol 2011, 11:6-13.

28. Rudolf I, Mendel J, Sikutová S, Svec P, Masaríková J, Nováková D, Bunková L, Sedlácek I, Hubálek Z: 16S rRNA gene-based identification of cultured bacterial flora from host-seeking Ixodes ricinus, Dermacentor reticulates and Haemaphysalis concinna ticks, vectors of vertebrate pathogens. Folia Microbiol 2009, 54:419-428

29. Dillon RH, Dillon VM: The gut bacteria of insects: nonpathogenic interactions. Annu Rev Entomol 2004, 49:71-92.

30. Teng K, Jiang Z: Economic insect Fauna of China, Fasc 39, Acari: Ixodidae. Beijing: Science Press; 1991
31. Tenquisf JD, Charleston WAG: A revision of the annotated checklist of ectoparasites of terrestrial mammals in New Zealand. J R Soc N Z 2001, 31:481-542.

32. Hoogstraal H, Roberts FH, Kohls GM, Tipton VJ: Review of Haemaphysalis (Kaiseriana) longicornis, Neumann (Resurrected) of Australia, New Zealand, New Caledonia, Fiji, Japan, Korea, and northeastern China and U.S.S.R. and its parthenogenetic and bisexual populations (Ixodoidea, Ixodidae). J Parasitol 1968, 54:1197-1213.

33. Wu XB, Na RH, Wei SS, Zhu JS, Peng HJ: Distribution of tick-borne diseases in China. Parasit Vectors 2013, 6:119-127.

34. Yu X, Liang M, Zhang S, Liu Y, Li J, Sun Y, Zhang L, Zhang Q, Popov VL, Li C, Qu J, Li Q, Zhang Y, Hai R, Wu W, Wang Q, Zhan F, Wang X, Kan B, Wang S, Wan K, Jing H, Lu J, Yin W, Zhou H, Guan X, Liu J, Bi Z, Liu G, Ren J, et al: Fever with thrombocytopenia associated with a novel Bunyavirus in China. N Engl J Med 2011, 364:1523-1532.

35. Guan G, Moreau E, Liu J, Hao X, Ma M, Luo J, Chauvin A, Yin H: Babesia sp. BQ1(Lintan): molecular evidence of experimental transmission to sheep by Haemaphysalis qinghaiensis and Haemaphysalis longicornis. Parasitol Int 2010, 59:265-267.

36. Sun J, Liu Q, Lu L, Ding G, Guo J, Fu G, Zhang J, Meng F, Wu H, Song X, Ren D, Li D, Guo Y, Wang J, Li G, Liu J, Lin H: Coinfection with four genera of bacteria (Borrelia, Bartonella, Anaplasma, and Ehrlichia) in Haemaphysalis longicornis and Ixodes sinensis ticks from China. Vector Borne Zoonotic Dis 2008, 8:791-795.

37. Lee MJ, Chae JS: Molecular detection of Ehrlichia chaffeensis and Anaplasma bovis in the salivary glands from Haemaphysalis longicornis ticks. Vector Borne Zoonotic Dis 2010, 10:411-413.

38. Zou Y, Jin H, Wang Q, Fu Z, Gao H, Liu P, Liu Q, Chen L: Molecular detection of Anaplasma phagocytophilum in Ixodid ticks in Hebei Province, China. Vector Borne Zoonotic Dis 2011, 11:1323-1327.

39. Lee JH, Park HS, Jang WJ, Koh SE, Park TK, Kang SS, Kim BJ, Kook YH, Park KH, Lee SH: Identification of the Coxiella sp. detected from Haemaphysalis longicornis ticks in Korea. Microbiol Immunol 2004, 48:125-130.

40. Lee JH, Park HS, Jung KD, Jang WJ, Koh SE, Kang SS, Lee IY, Lee WJ, Kim BJ, Kook YH, Park KH, Lee SH: Identification of the spotted fever group rickettsiae detected from Haemaphysalis longicornis ticks in Korea. Microbiol Immunol 2003, 47:301-304.

41. Tian W, Zhang Z, Moldenhauer S, Guo Y, Yu Q, Wang L, Chen M: Detection of Borrelia burgdorferi from ticks (Acari) in Hebei Province, China. J Med Entomol 1998, 35:95-98.

42. Yin H, Luo J: Ticks of small ruminants in China. Parasitol Res 2007, 101:S187-S189.

43. Yin H, Lu W, Luo J: Babesiosis in China. Trop Anim Hlth Prod 1997, 29:11S-15S.

44. Li Y, Luo J, Guan G: Experimental transmission of Theileria uilenbergi infective for small ruminants by Haemaphysalis longicornis and Haemaphysalis qinghaiensis. Parasitol Res 2009, 104:1227-1231.

45. Li Y, Luo J, Liu Z, Guan G, Gao J, Ma M, Dang Z, Liu A, Ren Q, Lu B, Liu J, Zhao H, Li J, Liu G, Bai Q, Yin H: Experimental transmission of Theileria sp. (China 1) infective for small ruminants by Haemaphysalis longicornis and Haemaphysalis qinghaiensis. Parasitol Res 2007, 101:533-538.

46. Ahmed J, Yin $H$, Schnittger $L$, Jongejan F: Ticks and tick-borne diseases in Aisa with special emphasis on China. Parasitol Res 2002, 88:S51-S55.

47. Chen Z, Yang X, Bu F, Yang X, Yang X, Yang X, Liu J: Ticks (Acari: Ixodoidea: Argasidae, Ixodidae) of China. Exp Appl Acarol 2010, 51:393-404.

48. Liu J, Liu Z, Zhang Y, Yang X, Gao Z: Biology of Dermacentor silvarum (Acari: Ixodidae) under laboratory conditions. Exp Appl Acarol 2005, 36:131-138.

49. Wilson $\mathrm{KH}$, Blitchington RB, Greene RC: Amplification of bacterial $16 \mathrm{~S}$ ribosomal DNA with polymerase chain reaction. J Clin Microbiol 1990, 28:1942-1946

50. Larkin MA, Blackshields G, Brown NP, Chenna R, Mcgettigan PA, Mcwilliam H, Valentin F, Wallace IM, Wilm A, Lopez R, Thompson JD, Gibson TJ, Higgins DG: Clustal W and clustal X version 2.0. Bioinformatics 2007 23:2947-2948

51. Tamura K, Dudley J, Nei M, Kumar S: MEGA4: molecular evolutionary genetic analysis (MEGA) software, version 4.0. Mol Biol Evol 2007 24:1596-1599.

52. Felsenstein J: Confidence limits on phylogenies: an approach using the bootstrap. Evolution 1985, 39:783-791.

53. Noda H, Munderloh UG, Kurtti TJ: Endosymbionts of ticks and thei relationship to Wolbachia spp. and tick-borne pathogens of humans and animals. Appl Environ Microbiol 1997, 63:3926-3932. 
54. Niebylski ML, Schrumpf ME, Burgdorfer W, Fischer ER, Gage KL, Schwan TG: Rickettsia peacockii sp. nov., a new species infecting wood ticks, Demacentor andersoni, in Western Montana. Int I Syst Bacteriol 1997, 47:446-452.

55. Liu L, Li L, Liu J, Hu Y, Liu Z, Guo L, Liu J: Coinfection of Dermacentor silvarum Olenev (Acari: Ixodidae) by Coxiella-like, Arsenophonus-like, and Rickettsia-like symbionts. Appl Environ Microbiol 2013, 79:2450-2454.

56. Grindle N, Tyner JJ, Clay K, Fuqua C: Identification of Arsenophonus-type bacteria from the dog tick Dermacentor variabilis. I Invertebr Pathol 2003, 83:264-266.

57. Zou Y, Wang Q, Fu Z, Liu P, Jin H, Yang H, Gao H, Xi Z, Liu Q, Chen L: Detection of spotted sever group Rickettsia in Haemaphysalis longicornis from Hebei Province, China. J Parasitol 2011, 97:960-962.

58. Heise SR, Elshahed MS, Little SE: Bacterial diversity in Amblyomma americanum (Acari: Ixodidae) with a focus on members of the genus Rickettsia. J Med Entomol 2010, 47:258-268.

59. Moreno CX, Moy F, Daniels TJ, Godfrey HP, Cabello FC: Molecular analysis of microbial communities identified in different developmental stages of Ixodes scapularis ticks from Westchester and Dutchess Counties, New York. Environ Microbiol 2006, 8:761-772.

60. Duron O, Bouchon D, Boutin S, Bellamy L, Zhou L, Engelstadter J, Hurst GD: The diversity of reproductive parasites among arthropods: Wolbachia do not walk alone. BMC Biol 2008, 6:27-38.

61. Reinhardt C, Aeschlimann A, Hecker H: Distribution of Rickettsia-like microorganisms in various organs of an Ornithodoros moubata laboratory strain (Ixodoidae, Argasidae) as revealed by electron microscopy. Z Parasitenkd 1972, 39:201-209.

62. Lalzae I, Harrus S, Mumcuoqlu KY, Gottlieb Y: Composition and seasonal variation of Rhipicephalus turanicus and Rhipicephalus sanguineus bacterial communities. Appl Environ Microbiol 2012, 78:4110-4116.

63. Ahantarig A, Malaisri P, Hirunkanokpun S, Sumrandee C, Trinachartuanit W, Baimai V: Detection of Rickettsia and a novel Haemaphysalis shimoga symbiont bacterium in ticks in Thailand. Curr Microbiol 2011, 62:1496-1502.

64. Bernasconi MV, Casati S, Peter O, Piffaretii JC: Rhipicephalus ticks infected with Rickettsia and Coxiella in Southern Switzerland (Canton Ticino). Infect Genet Evol 2002, 2:111-120.

65. Machado-Ferreira E, Dietrich G, Hojgaard A, Levin M, Piesman J, Zeidner NS, Soares CA: Coxiella symbionts in the Cayenne tick Amblyomma cajennense. Microb Ecol 2011, 62:134-142.

66. Mediannikov O, Ivanov L, Nishikawa M, Saito R, Sidelnikov YN, Zdanovskaya $\mathrm{NI}$, Tarasevich IV, Suzuki H: Molecular evidence of Coxiella-like microorganism harbored by Haemaphysalis concinnae ticks in the Russian Far East. Ann N Y Acad Sci 2003, 990:226-228.

67. Reeves WK: Molecular evidence for a novel Coxiella from Argas monolakensis (Acari: Argasidae) from Mono Lake, California, USA. Exp Appl Acarol 2008, 44:57-60.

68. Reeves WK, Loftis AD, Priestley RA, Wills W, Sanders F, Dasch GA: Molecular and biological characterization of a novel Coxiella-like agent from Carios capensis. Ann N Y Acad Sci 2005, 1063:343-345.

69. Baldridge GD, Burkhardt NY, Simser JA, Kurtti TJ, Munderloh UG: Sequence and expression analysisi of the ompA gene of Rickettsia peacockii, an endosymbiont of the Rocky Mountain wood tick, Dermacentor andersoni. Appl Environ Microbiol 2004, 70:6628-6636.

70. Lo N, Beninati T, Sassera D, Bouman EA, Santagati S, Gern L, Sambri V, Masuzawa T, Gray JS, Jaenson TG, Bouattour A, Kenny MJ, Guner ES, Kharitonenkov IG, Bitam I, Bandi C: Widespread distribution and high prevalence of an alpha-proteobacterial symbiont in the tick Ixodes ricinus. Environ Microbiol 2006, 8:1280-1287.

71. Mira A, Moran NA: Estimating population size and transmission bottlenecks in maternally transmitted endosymbiotic bacteria. Microb Ecol 2002, 44:137-143.

72. Weeks AR, Reynolds KT, Hoffmann AA: Wolbachia dynamics and host effects: what has (and has not) been demonstrated? Trends Ecol Evol 2002, 7:257-262

\section{doi:10.1186/1756-3305-6-310}

Cite this article as: Liu et al:: Microbial communities and symbionts in the hard tick Haemaphysalis longicornis (Acari: Ixodidae) from north China. Parasites \& Vectors 2013 6:310.

\section{Submit your next manuscript to BioMed Central and take full advantage of:}

- Convenient online submission

- Thorough peer review

- No space constraints or color figure charges

- Immediate publication on acceptance

- Inclusion in PubMed, CAS, Scopus and Google Scholar

- Research which is freely available for redistribution 